\title{
Dr. Leslie A. Geddes 1921-2009: A Pioneer in Cardiovascular Engineering
}

\author{
(Received 8 January 2010; accepted 13 January 2010; published online 17 February 2010)
}

Iconic American inventor, Thomas Alva Edison, once said, "Genius is one percent inspiration and 99 percent perspiration. I never did anything worth doing by accident, nor did any of my inventions come by accident. They came by work." By this definition, Dr. Leslie A. Geddes was truly a genius. Like most prolific inventors, Dr. Geddes had a wide variety of hobbies and interests, but he focused the majority of his efforts as a Biomedical Engineer on his unparalleled passion for cardiovascular devices.

His unique combination of inspiration and hard work throughout his 88 years resulted in 23 books, 36 patents and over 850 scientific papers. He was named Fellow in at least eight scientific societies and was honored with numerous awards including the Edison Gold Medal from IEEE (1994), the Henri Busignies award from the Radio Club of America (1997), the Cor Vitae award from the American Heart Association (2005), and the United States National Medal of Technology (2006). These are but a few of his recognitions. Although Dr. Geddes savored each and every milestone, accomplishment, and award, they fail to convey the essence of his personality which genuinely endeared him to friends and colleagues around the world.

Upon meeting Dr. Geddes, it was abundantly clear that he loved his work. So much so that he would never call it work, it was a hobby that he treated with passionate devotion. His workday never ended. He would incorporate the opportunity for innovation and discovery into every aspect of his daily rituals and interactions. He even admitted that he occasionally discovered the solution to a conundrum in his sleep.

He had an insatiable curiosity and voracious appetite for information. With each new idea, he would dig into the scientific literature surrounding the topic and work his way back through time, mapping the evolution of current thought to find the core of its origin. These literature excavations led him to write numerous articles. The IEEE EMBS Magazine Retrospectroscope column became his regular pulpit for explaining the intersection of engineering and medicine in history.

As he was mining the scientific literature, he would go where the data would lead him, investigating many tangents along the way. For each article he read, he would ingest the data presented and form independent conclusions to compare to those of the authors. To catalogue the key findings in each piece of the

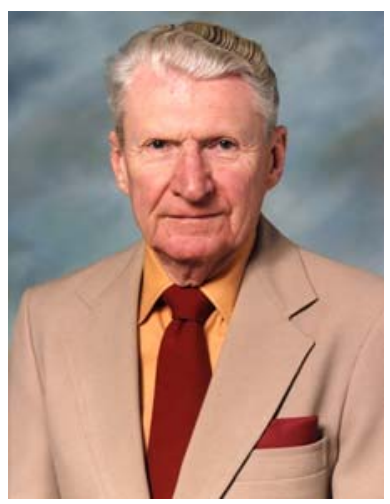

Dr. Leslie A. Geddes, 1921-2009.

literature, Dr. Geddes would fill the upper right hand corner with the authors' name, the publication date and a few key findings and phrases that would trigger his memory. Through this process, Dr. Geddes generated countless ideas for experiments from gaps in the knowledge base and what he believed to be falsehoods propagated with insufficient evidence.

Yet Geddes was not unduly influenced by the literature or by conventional thinking. He often said, "If anybody in the laboratory gets a new idea, we'll drop everything and help him or her do the first experiment." He was a champion of "creative play" in the laboratory, personally building models and prototypes to demonstrate proof of concept. He loved history, but he worshiped creativity.

The direct and indirect measurement of blood pressure was one key area that held his interest. His extensive digging evolved into numerous historical articles, two books, and a myriad of contributions and devices that spanned his entire career. When presented with an indirect pneumatic method of measuring mean blood pressure, Dr. Geddes methodically worked to determine the algorithms for systolic and diastolic arterial pressure, establishing appropriate cuff sizes and deflation rates. His extensive contributions laid the foundation for the worldwide acceptance of the oscillometric method of blood pressure measurement. Decades later, Dr. Geddes circled back around to develop an optical adaptation of the oscillometric method to meet the unique challenges of indirectly measuring blood pressure in the smallest humans and animals. 


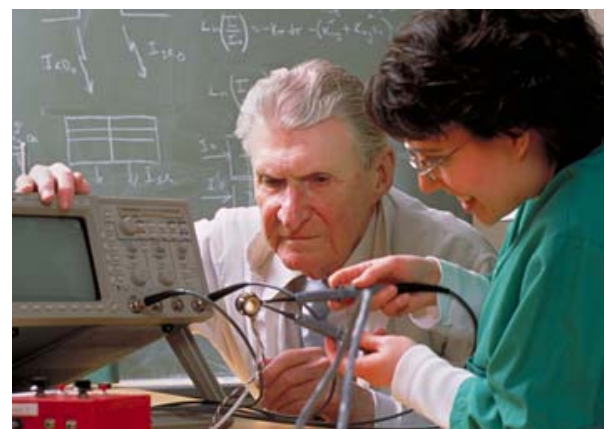

Leslie Geddes, Purdue's Showalter Distinguished Professor Emeritus of Bioengineering, and doctoral candidate Rebecca Roeder, test a device they invented that uses optical techniques to measure the vital signs of premature infants (Purdue file photo/Vincent Walter).

Dr. Geddes was completely unafraid of failure and found opportunity in every data set. He believed that research was all about thinking, doing, learning and rethinking. With each experiment, Dr. Geddes would carefully examine the data and spend the time to think about what it was trying to tell him. He would say, "Doing research is like peeling onions; you peel off the layers of ignorance crying all the way."

Dr. Geddes' curiosity and excitement for research was infectious. The people around him were quickly pulled in by his intense enthusiasm. As a team, ideas were explored, experiments were formulated and plans were devised. Everyone was involved. You never worked for Dr. Geddes, you always worked with Dr. Geddes. His conviction for teamwork paralleled his passion for teaching.

Dr. Geddes was a great teacher and mentor. One of his most special qualities was his ability to include any person in the learning process; no-one was too young, too old, or too inexperienced. His research teams would include high school students, undergraduate students, graduate students, medical residents and fellows, and doctoral level colleagues. All were treated with equal respect. Even children took pleasure in spending time with and learning from Dr. Geddes. With his approachable and welcoming personality, he made learning enjoyable. He had an uncanny ability to pull you in, and without realizing it you would become an active pursuant in his experimental quest.
His greatest legacy endures in his students. Dr. Geddes' work in the area of cardiac fibrillation and defibrillation (another interest that spanned his entire career) exemplified his commitment to teaching and mentoring. His initial interest in the mechanism and induction of fibrillation quickly spread to a desire to completely understand defibrillation. Drs. Willis Tacker, Joe Bourland, and Charles Babbs were quickly drawn into this team. For the span of decades, they worked together with a multitude of graduate students to investigate the principles of defibrillation, defibrillation electrodes, defibrillation waveforms and optimal defibrillator design. When they discovered that incoming medical students were uninformed about the facts and serious consequences of ventricular fibrillation, they created an award winning instructional video. When there wasn't an adequate forum for the discussion of the state of current defibrillation research, they started the international Cardiac Defibrillation Conference at Purdue in 1975.

Throughout his career, Dr. Geddes mentored over $30 \mathrm{Ph} . \mathrm{D}$. students and nearly 80 master's degree students. Many of them have gone on to achieve great things and give credit to him for teaching them the skills and determination they needed to succeed. Although he officially "retired" in 1991, he never stopped learning, teaching, and inventing. He often insisted, "I'm not finished yet." His last trip to the university was on the Tuesday before his passing. He didn't want to miss the opportunity to demonstrate the indirect measurement of blood pressure to his Medical Device Accidents class. Though his body was weak, his mind was still incredibly sharp.

His office is now quiet, but one can walk into it and be reminded of so many years of experience, so many years of educating eager young minds. He will be truly missed. However, as Dr. Geddes' colleagues, we are bound to share his influence in our lives; his eternal optimism, his zest for living, and his care for others. Through solving scientific problems, he taught those around him a better way of life.

\section{Rebecca Roeder and Cynthia Ferguson}

Purdue University

Electronic mail: fergusoc@purdue.edu 